\title{
Factors Determining Operation of Lip Seal in the Sealed Gap of the Hydraulic Props of Powered Supports
}

\author{
Gennady Buyalich ${ }^{1, *}$, Maxim Byakov ${ }^{2}$, and Konstantin Buyalich ${ }^{1}$ \\ ${ }^{1}$ T.F. Gorbachev Kuzbass State Technical University, Underground Mining Department, 650000 \\ Kemerovo, Vesennya st. 28, Russian Federation \\ ${ }^{2}$ JSC «SUEK-Kuzbass», Vasilyeva street 1, Leninsk-Kuznetsky, 652507, Russian Federation
}

\begin{abstract}
The article considers the factors that directly influence the operation of the lip seals to seal the gap between the piston and the working cylinder in hydraulic props of mechanized supports, this directly affects the tightness of the props and, as a consequence, the safety of work in the production face. A description is given of these factors, which is supported by practical calculations obtained from the results of finite element modeling of lip seals of various designs at different pressures of the working fluid and sealed gaps. The problems of sealing rough surfaces with rubber-like materials are considered. The classification of these factors according to the degree of generalization and the functional interaction between each other is proposed.
\end{abstract}

\section{Introduction}

At present, due to the deepening of mining operations, the mining and geological conditions of operation of mechanized complexes deteriorate. At the same time, the total number of mechanized complexes is decreasing, and their productivity is increasing, which indicates an intensification of the coal mining process. All this imposes higher demands on the level of operation reliability of complex mechanized faces.

The main elements of the powered support that directly receive rock pressure and provide reliable and safe conditions for work and mechanisms in the production face, are hydraulic props, the level of tightness of which determines the operation of the system as a whole [1-5].

\section{Research theory}

A hydraulic prop is a single or double hydraulic power cylinder which takes up the force from rock strata due to the pressure of the hydraulic fluid in its piston cavity (Fig. 1) [6-9].

\footnotetext{
* Corresponding author: gdb@kuzstu.ru
} 


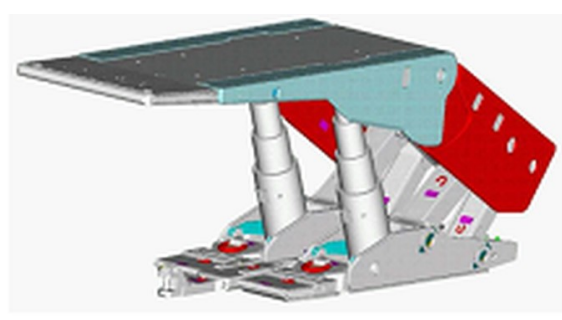

a)

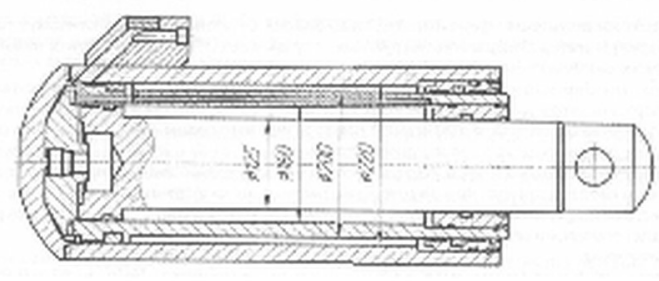

(b)

Fig. 1. Powered support unit (a) and a hydraulic prop of double extension (b).

The principle of operation of the seal is as follows. In reciprocating motion, the surface of the working cylinder 1 (Fig.2), on the one hand, and the surface of the groove of piston 2 , on the other hand, contact each other via sealing unit 3 , which is a lip seal.

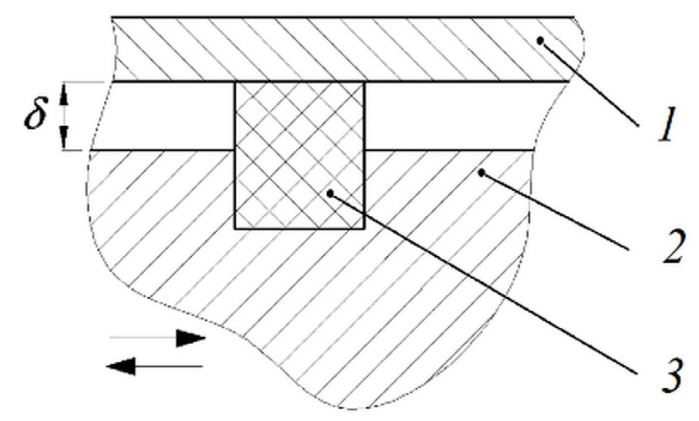

Fig. 2. Scheme of overlapping the sealed gap $\delta$ ( 1 - working cylinder, 2 - piston, 3 - seal).

The size of the sealing gap $\delta$ is determined by tolerance zones for manufacture of a piston and a cylinder, as well as by radial deformations of the wall of the working cylinder depending on the design and geometric dimensions of the hydraulic prop, its extension, material properties, and the size and type of applied loads from hydraulic fluid pressure and collapsing rocks $[8,10-14]$.

The surface to be sealed is a network of interconnected microchannels formed by microirregularities that are covered by seal 1 (Figure 3 ) by pressing it into the micro-irregularities of the sealed surface 2. This process takes place under the action of pressure in lip seal $P k$ on the contact with the surface. The amount of leakage through a network of microchannels characterizes the level of tightness and is determined by the height of the microirregularities of the sealed surface (the roughness of the surface during machining and various damages - scratches in operation), the value of the contact pressure $P k$, the value of the lockable pressure of the hydraulic fluid $\mathrm{p}$, the width of the seal $B$, the viscosity of the hydraulic fluid and properties of the packing material [15-18].

The scheme of interaction of the seal with the contacting surface and the cover of the microchannels on the sealing surface is shown in Fig. 3. 


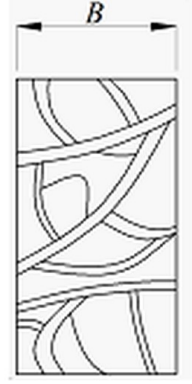

(a) The microchannels at the sealing surface

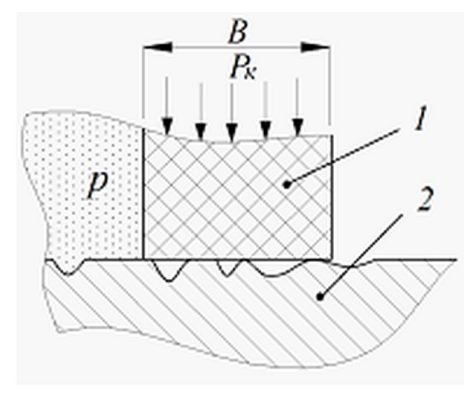

(b) The interaction seal with the surface

Fig. 3. Scheme of interaction of the seal (1) with contacting surface (2) ( $B$ - width of sealing).

The solution was carried out in two stages. First, the strains and stresses of the lip seal were identified caused by the preload when it was mounted, and then the working pressure of the hydraulic fluid was applied.

In the solution, the deformation model was used for rubber-like materials with the function of the Mooney-Rivlin strain energy density distribution.

Figure 4 shows the results of calculations of the stress-strain state of the seal by the finite elements method in accordance with GOST 6678-72 at hydraulic fluid pressure $\mathrm{P}=$ $50 \mathrm{MPa}$ and the value of the sealing gap $\delta=190 \mu \mathrm{m}$, with the locking ratio being 1.01 , and the safety factor 5.2 .

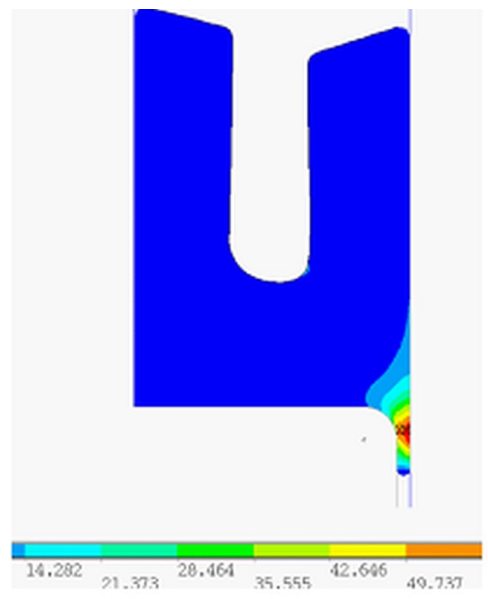

(a) The stresses von Mises
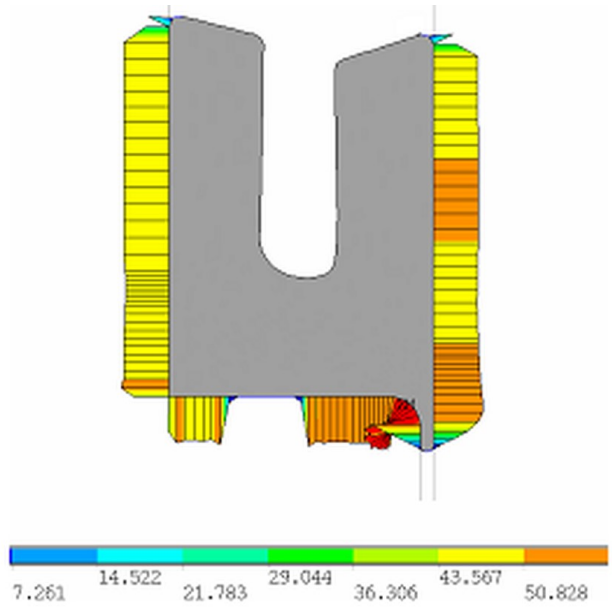

(b) The contact pressures

Fig. 4. The nature of stresses distribution von Mises in MPa (a) and contact pressures in $\mathrm{MPa}$ (b) for the lip seal as per GOST 6678-72 at the working fluid pressure $P=50 \mathrm{MPa}$ and the value of the sealed gap $\delta=190 \mu \mathrm{m}$.

Based on the results of finite element modeling of lip seals of various types, the following features of their behavior in various designs of hydraulic props were identified.

As the pressure of the hydraulic fluid increases, squeezing out of the seal into the gap sharply increases and the safety factor decreases (Fig. 5).

As the sealing gap increases, squeezing out of the seal material into the gap $(L)$ abruptly increases and the safety factor $(n)$ abruptly decreases, down to the critical values. 


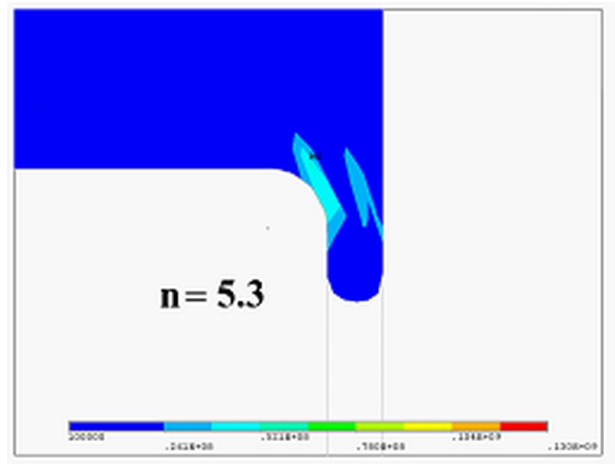

(a) $P=50 \mathrm{MPa}$

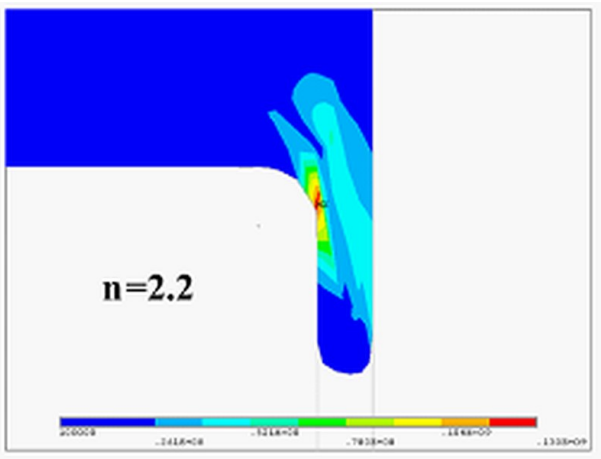

(b) $P=70 \mathrm{MPa}$

Fig. 5. The nature of stresses distribution von Mises in MPa, squeezing out of the seal in the gap and the values of safety factor $(n)$ for the lip seal as per GOST 6678-72 at the size of the sealed gap $\delta=190 \mu \mathrm{m}$ and the pressure of hydraulic liquid: a) $P=50 \mathrm{MPa}$; b) $P=70 \mathrm{MPa}$.

The locking factor of the hydraulic fluid increases sharply with increasing working pressure (Fig. 6), which has a positive effect on tightness of the sealing unit, as on the recommendations of various authors it should be more than one.

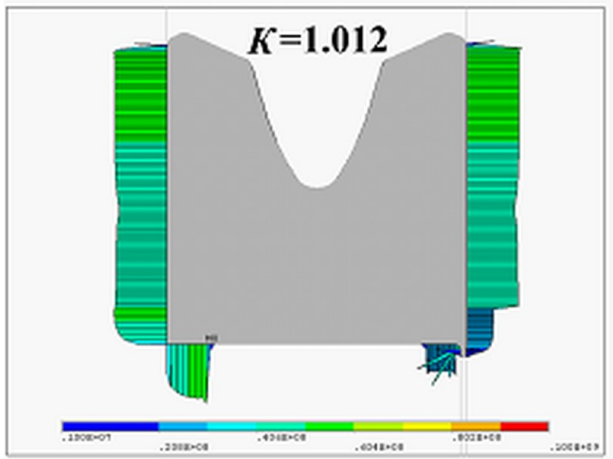

(a) $P=50 \mathrm{MPa}$

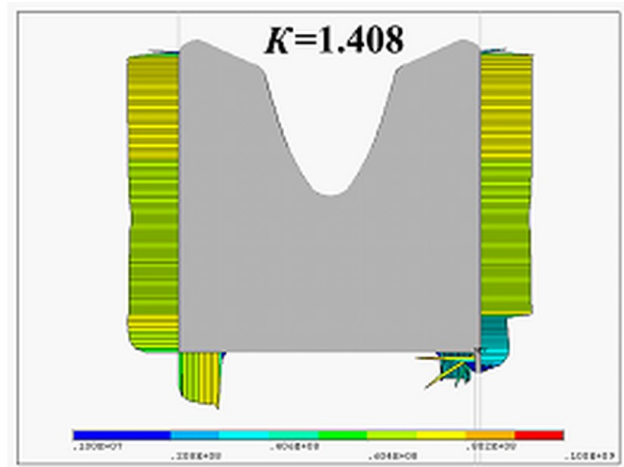

(b) $P=70 \mathrm{MPa}$

Fig. 6. Nature of contact pressures distribution in MPa and the liquid locking factor values $(K)$ for the lip seal as per GOST 6678-72 at the size of sealed gap $\delta=190 \mu \mathrm{m}$ and hydraulic liquid pressure: a) $P=50 \mathrm{MPa}$; b) $P=70 \mathrm{MPa}$.

Designs of lip seals with backing rings and designs with small non-uniformity of contact pressures at high values of hydraulic liquid pressure decrease squeezing out of seal material in the gap.

\section{Results and Discussion}

On the basis of the foregoing, it is possible to single out the main factors affecting the operation of the sealing element in covering the clearance between the working cylinder and the piston in hydraulic props of powered supports, on which prevention of the loss of tightness of the hydraulic props and keeping the working capacity of the mining system depends.

Figure 7 shows the main factors on which the operation of lip seals in the sealed gap of the hydraulic prop of the powered support depends. Arrows indicate the direction of subordination of factors towards their enlargement. For example, the sealing parameters 
(symbol 4) are determined by its design, shape and dimensions (symbol 4.1), the properties of its materials (symbol 4.2) and preload (symbol 4.3).

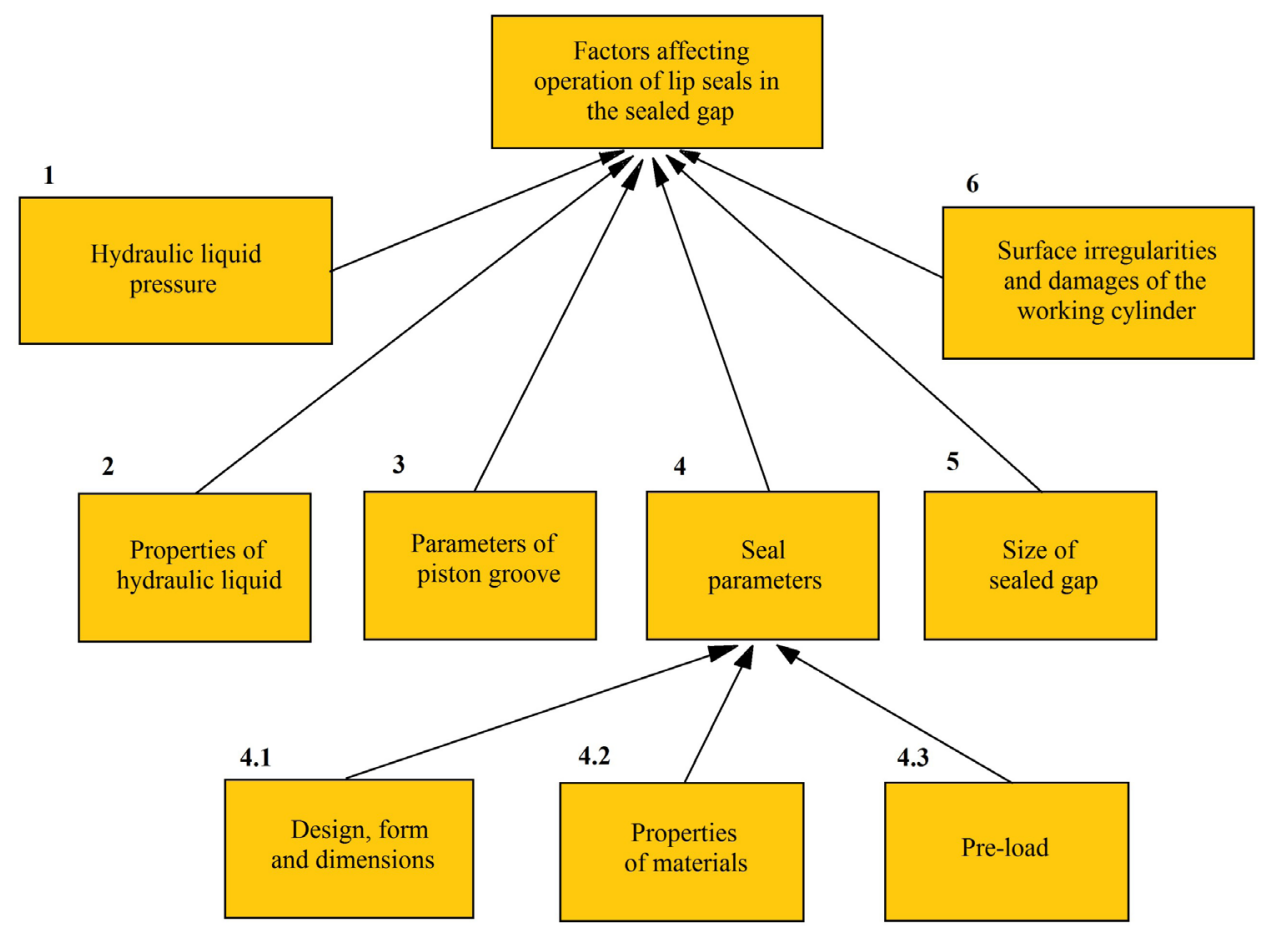

Fig. 7. Classification of factors effecting the functioning of lip seals in the sealed gap of hydraulic props of powered supports.

\section{Conclusion}

The operation of lip seals in covering the sealed gap in the hydraulic props of the powered supports is determined by their design and geometric parameters, the value of their pre-load during installation, the properties of the seal material and hydraulic fluid, the parameters of the piston groove, the roughness of the sealing surface and the gap between the piston and the working cylinder. The integrated consideration of these parameters for the actual props in the specific operating conditions of the mining system will allow us to avoid loss of tightness of the main support assembly and to increase the reliability and safety of mining operations.

\section{References}

1. V. I. Klishin, Y. V. Matviets. Fiziko-Tekhnicheskie Problemy Razrabotki Poleznykh Iskopaemykh, 2, 23, (1993)

2. S. V. Klishin, V. I. Klishin, G. Yu. Opruk, J. Min. Sci, 49(6), 932, (2013)

3. V. I. Klishin, Yu. S. Fokin, Yu. M. Lekontsev, D. I. Kokoulin, Gornyi Zhurnal, 12, 112 (2005)

4. V. I. Klishin, Journal of Mining Science, 30(4), 390 (1995)

5. V. I. Klishin, T. M. Tarasik, Journal of Mining Science, 37(1), 77 (2001) 
6. D. A. Chinakhov, Applied Mechanics and Materials, 52, 442 (2011)

7. D. A. Chinakhov, Applied Mechanics and Materials, 762, 717 (2013)

8. G. D. Buyalich, A. V. Anuchin, K. P. Serikov, IOP Conf. Series: Materials Science and Engineering, 127(1), 012012 (2016)

9. G. D. Buyalich, B. A. Aleksandrov, Y. A. Antonov, V. V. Voyevodin, Journal of Mining Science, 36(5), 487, (2000)

10. G. D. Buyalich, K. G. Buyalich, V. V. Voevodin, IOP Conference Series: Materials Science and Engineering, 127(1), 012034 (2016)

11. A. Putnic, Archives of Mining Sciences, 60(2), 595 (2015)

12. S. V. Uvakin, Ugol, 7, 53 (2016)

13. G. D. Buyalich, K. G. Buyalich, V. Yu. Umrikhina, IOP Conf. Series: Materials Science and Engineering, 142, 012120 (2016)

14. G. Buyalich, K. Buyalich, M. Byakov, E3S Web of Conferences, 21, 03018 (2017)

15. G. D. Buyalich, K. G. Buyalich, Taishan Academic Forum - Project on Mine Disaster Prevention and Control, 167 (2014)

16. E. N. Pashkov, G. R. Zijakaev, M. V. Tsigankova, Applied Mechanics and Materials, 379, 91 (2013)

17. M. V. Novoseltseva, I. A. Masson, E. N. Pashkov, IOP Conference Series: Materials Science and Engineering, 127(1), 012007 (2016)

18. A. V. Krainov, E. N. Pashkov, R. E. Lushnikov, V. A. Arkhipov, Key Engineering Materials, 685, 280 (2016) 